\title{
Application of monitoring guidelines to induced seismicity in Italy
}

\author{
Thomas Braun (D) - Stefania Danesi • Andrea Morelli
}

Received: 5 February 2019 / Accepted: 19 December 2019/Published online: 2 January 2020

(C) The Author(s) 2019

\begin{abstract}
Public concern about anthropogenic seismicity in Italy first arose in the aftermath of the deadly $\mathrm{M} \approx$ 6 earthquakes that hit the Emilia-Romagna region (northern Italy) in May 2012. As these events occurred in a (tectonically active) region of oil and gas production and storage, the question was raised, whether stress perturbations due to underground industrial activities could have induced or triggered the shocks. Following expert recommendations, in 2014, the Italian Oil \& Gas Safety Authority (DGS-UNMIG, Ministry of Economic Development) published guidelines (ILG - Indirizzi e linee guida per il monitoraggio della sismicità, delle deformazioni del suolo e delle pressioni di poro nell'ambito delle attività antropiche), describing regulations regarding hydrocarbon extraction, waste-water injection and gas storage that could also be adapted to other technologies, such as dams, geothermal systems, $\mathrm{CO}_{2}$ storage, and mining. The ILG describe the framework for the different actors involved in monitoring activities, their relationship and responsibilities, the
\end{abstract}

\section{T. Braun $(\bowtie)$}

Istituto Nazionale di Geofisica e Vulcanologia, Rome, Italy

e-mail: thomas.braun@ingv.it

S. Danesi · A. Morelli

Istituto Nazionale di Geofisica e Vulcanologia, Bologna, Italy

S. Danesi

e-mail: stefania.danesi@ingv.it

A. Morelli

e-mail: andrea.morelli@ingv.it procedure to be followed in case of variations of monitored parameters, the need for in-depth scientific analyses, the definition of different alert levels, their meaning and the parameters to be used to activate such alerts. Four alert levels are defined, the transition among which follows a decision to be taken jointly by relevant authorities and industrial operator on the basis of evaluation of several monitored parameters (micro-seismicity, ground deformation, pore pressure) carried on by a scientific-technical agency. Only in the case of liquid reinjection, the alert levels are automatically activated on the basis of exceedance of thresholds for earthquake magnitude and ground shaking - in what is generally known as a Traffic Light System (TLS). Istituto Nazionale di Geofisica e Vulcanologia has been charged by the Italian oil and gas safety authority (DGSUNMIG) to apply the ILG in three test cases (two oil extraction and one gas storage plants). The ILG indeed represent a very important and positive innovation, as they constitute official guidelines to coherently regulate monitoring activity on a national scale. While pilot studies are still mostly under way, we may point out merits of the whole framework, and a few possible critical issues, requiring special care in the implementation. Attention areas of adjacent reservoirs, possibly licenced to different operators, may overlap, hence making the point for joint monitoring, also in view of the possible interaction between stress changes related to the different reservoirs. The prescribed initial blanklevel monitoring stage, aimed at assessing background seismicity, may lose significance in case of nearby active production. Magnitude - a critical parameter used to 
define a possible step-up in activation levels - has inherent uncertainty and can be evaluated using different scales. A final comment considers the fact that relevance of TLS, most frequently used in hydraulic fracturing operations, may not be high in case of triggered tectonic events.

Keywords Anthropogenic seismicity · Monitoring guidelines $\cdot$ Alert system $\cdot$ Italy

\section{Introduction}

Since the inception of the use of hydraulic fracturing for shale gas production, human-induced seismicity has become a subject of increasing interest, especially in the USA and Canada (e.g. Davis and Frohlich 1993; McGarr et al. 2002; Ellsworth 2013). Many studies have since been published on anthropogenic seismicity. A review of human-induced earthquakes on a global scale was given by Foulger et al. (2017); Grigoli et al. (2017) published a European perspective about challenges in monitoring, discrimination, and management of induced seismicity related to underground industrial activities, while Braun et al. (2018b) gave an overview about the state of the art of anthropogenic seismicity in Italy. Doglioni (2018) proposed a classification of induced seismicity, distinguishing four different mechanisms causing earthquakes with anthropogenic origin. Dahm et al. (2013) and Cesca et al. (2013b) gave recommendations for the discrimination of human-related and natural seismicity and proposed a probabilistic approach to discriminate between induced, triggered, and natural earthquakes based on the modelling of depletioninduced stress changes and seismological source parameters (Dahm et al. 2015). Italian geology is not suitable for shale gas exploitation; however, concerns about anthropogenic seismicity in Italy came up after the deadly $\mathrm{M}_{\mathrm{W}}=6.2$ Emilia-Romagna (northern Italy) earthquake in May 2012 (Scognamiglio et al. 2012; Cesca et al. 2013a). Since this seismic sequence occurred in the vicinity of gas and oil production sites, the question surfaced, whether variations in crustal stress accompanying hydrocarbon extraction might have influenced the generation of these earthquakes. The Italian Department of Civil Protection appointed an international committee (ICHESE, International Commission on Hydrocarbon Exploration and Seismicity in the Emilia region) to analyse all available geological, geophysical, and industrial information and to investigate whether the 2012 earthquake sequence could have been induced or triggered by industrial activities in the area. In their conclusions, the committee argued that only the Cavone oilfield, the Casaglia geothermal field, and the Minerbio gas storage plant were located in the surroundings of the main shocks, and concluded that "it is highly unlikely that the activities of hydrocarbon exploitation and the geothermal activity have produced sufficient stress change to generate an 'induced' seismic event', but that they could not rule out the possibility that operations at the Cavone oilfield "may have contributed to trigger" "the Emilia seismic activity" (ICHESE 2014). The report originated public concern, as well as a debate about implications of underground technologies, and it hit the news as a suggestion that human activities might indeed have caused deadly earthquakes (Cartlidge, 2014), with a mechanism never before seriously considered in Italy. In 2014, the Italian institute for environmental protection and research (Istituto Superiore per la Protezione e la Ricerca Ambientale, ISPRA) published a report about documented and presumed cases of triggered or induced seismicity in Italy (Fig. 1; ISPRA 2014). The Ministry for Economic Development (MISE), the EmiliaRomagna Regional Government, and the Italian Petroleum and Mining Industry Association (Assomineraria) and the company, owner of the oil plant, in 2014 promoted monitoring and research on the Cavone site (LabCavone, 2019), in an effort that led to the production of a fluid-geo-mechanical model that allowed to conclude that "the combined effects of fluid production and reinjection from the Cavone field were not a driver for the observed seismicity" (Astiz et al. 2014). Further studies considered unlikely that the combined effect of oil production and water injection from the main potential culprit, the Cavone oil field, could have influenced the occurrence of the earthquake sequence (e.g. Dahm et al. 2015; Juanes et al., 2016).

In the following years, the Italian government adopted disciplinary resolutions concerning gas and oil prospecting, research and exploitation (i.e. Legislative Decree D.L. 133/2014, Stability Law 2015, Stability Law 2016). The ICHESE (2014) report recommended that all existing and future activities of hydrocarbon exploitation (oil and gas production, wastewater re-injection, gas storage, geothermal energy production) would have to be subject to monitoring for seismicity, ground deformation and pore 


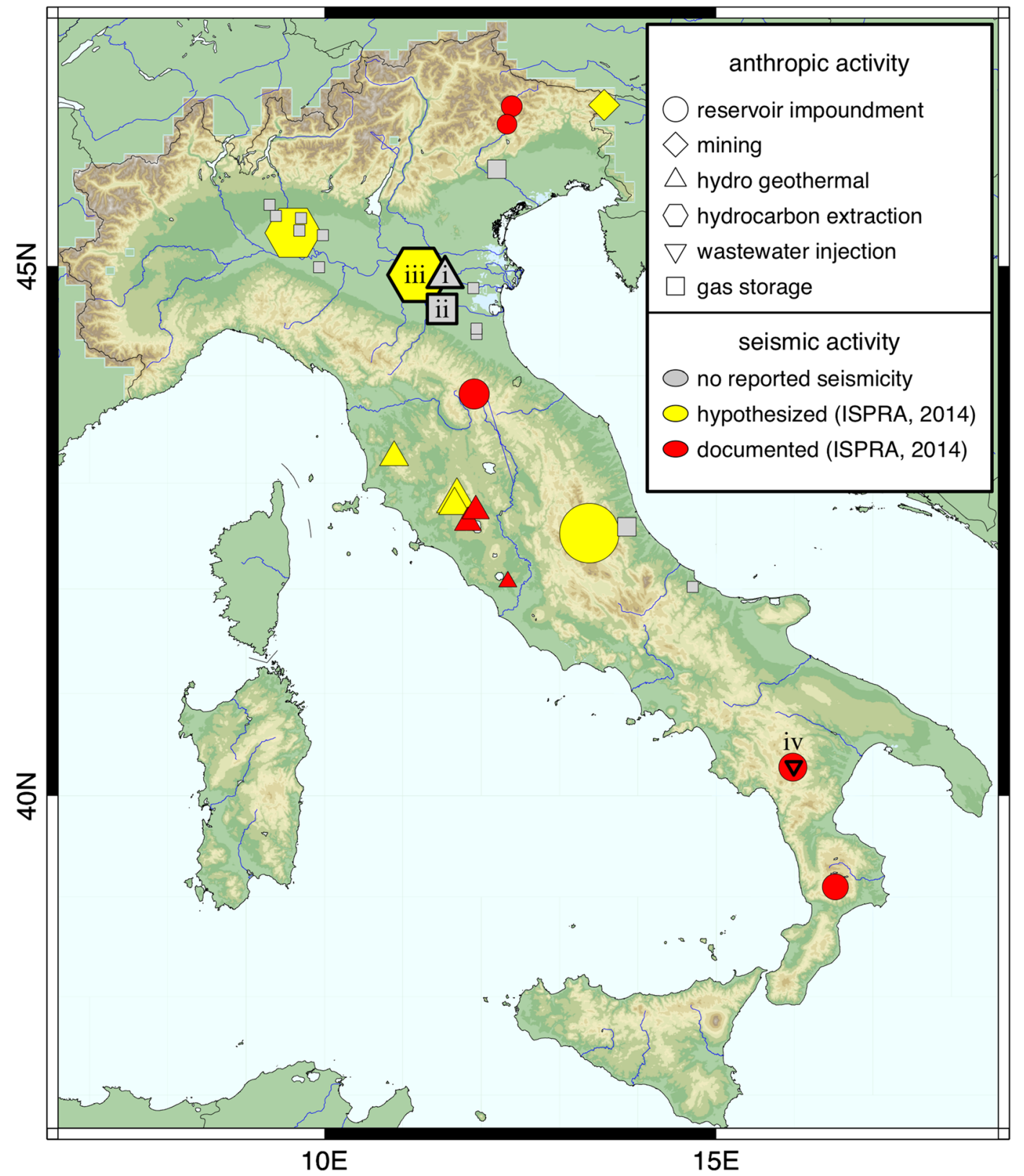

Fig. 1 Documented and hypothesised cases of triggered and induced seismicity in Italy (modified from Braun et al. 2018b): grey symbols represent human activity without reported

pressure by high-quality networks. To follow such recommendation, the Italian Oil \& Gas Safety Authority (DGS-UNMIG, Ministry of Economic Development) published guidelines (Dialuce et al. 2014) describing regulations for geophysical monitoring of hydrocarbon extraction, waste-water injection and gas storage. (For a more in-depth account of these seismicity, green and red symbols are magnitude scaled and depict, respectively, hypothesised and documented cases of triggered or induced seismicity (ISPRA 2014)

events see, e.g., Macini et al. 2015; Antoncecchi et al. 2017; Ciccone et al. 2017; Macini et al. 2017.)

In this short note, we briefly outline the essence of the monitoring guidelines, describe the experience of their first implementation (up to now, in experimental mode), provide a general picture of the current state of monitoring practices in Italy, 
mention some possibly sensitive issues, and comment on future perspectives.

1.1 Italian guidelines for monitoring effects of industrial activity on the subsurface

The Italian Oil \& Gas Safety Authority (DGS-UNMIG, a Directorate General of the Ministry of Economic Development) charged a group of experts to define guidelines following recommendations from the ICHESE (2014) report, for monitoring seismicity, ground deformation and pore pressure. The result of this effort (Indirizzi e linee guida per il monitoraggio della sismicità, delle deformazioni del suolo e delle pressioni di poro nell'ambito delle attività antropiche, ILG, Dialuce et al. 2014) represent the first effort towards systematic, well structured, public regulations regarding independent geophysical monitoring of underground anthropic activities in oil/gas operations (extraction, waste-water re-injection, storage) that could also be adapted to other technologies, such as dams, geothermal systems, $\mathrm{CO}_{2}$ storage, and mining. A more recent edition of the ILG concerning geothermal energy production has been published in 2016 (Terlizzese 2016).

The ILG describe standards for monitoring relevant geophysical observables; outline roles and responsibilities of the different actors involved in monitoring activities; define procedures to be followed in case of significant changes of the monitored parameters; pinpoint the need for in-depth scientific analyses; establish four different activation levels, along with their meaning and the criteria to be used to activate such alerts (Dialuce et al. 2014; Macini et al. 2015; Macini et al. 2017). In the case of reinjection of incompressible fluids (i.e. production waste waters), alert levels are automatically attributed following a threshold system controlled by a few seismic parameters: magnitude, peak ground velocity (PGV) and peak ground acceleration (PGA) - this is generally known as a Traffic Light System (e.g. Bommer et al. 2006; Baisch et al. 2019).

The monitoring scheme is focussed on a limited three-dimensional volume around the production reservoir. Special attention is requested to possible induced or triggered seismicity and/or ground deformation occurring within the so-called Inner Domain (Dominio Interno, DI), defined by widening the footprint of the oil-water contact in the reservoir by a distance, depending on the developed activity (2-3 km for gas storage, $5 \mathrm{~km}$ in case of fluid injection within the oilfield; the depth extent is also obtained by adding the same distance to reservoir depth). An Extended Domain (Dominio Esteso, DE) is also defined as an additional crustal volume of $5-10 \mathrm{~km}$ width around the DI, depending on the type of activity and oilfield dimension, where some looser conditions apply. The definition of finite volumes addressed for observation and monitoring assumes that any geo-mechanical or fluid propagation effect outside the External Domain should not be directly ascribed to the reservoir exploitation. In analogy with well-known Traffic Light Systems (e.g. Bommer et al. 2006; Baisch et al. 2019), the ILG introduce the socalled activation levels, which correspond to increasing size of seismic phenomena, and to increasing impact of the actions required.

The ILG define four activation levels - that in case of water re-injection are automatically set in exceedance of specific thresholds - and corresponding actions, namely:

- Green: Ordinary conditions (when monitored parameters are within background values)

- Yellow: Attention (when monitored parameters exceed background values; all actors involved are required to increase efforts and critically evaluate the evolution of the situation hourly or daily)

- Orange: Reduction of operations (a step up from the yellow level, when variations of monitored parameters and exploitation/storage activities appear correlated)

- Red: Stop of operations (a step up from the yellow or orange level, whenever actions undertaken in the previous activation level are not considered sufficient)

Within 10 days from the reduction or stop of activities, conditions to step back to a lower level, or restore background conditions, must be verified and decisions be taken accordingly. All transitions among these levels are regulated by decisions taken jointly by MISE, relevant local Regional government, and industrial operator, on the basis of scientific data and interpretation given by the monitoring agency (Struttura Preposta al Monitoraggio, SPM). The ILG guidelines therefore define characteristics and roles of a technical-scientific body with proved skills, entrusted with tasks of acquisition and analysis of data, and technical support to the competent regulatory authorities (Dialuce et al. 2014). 
For each hydrocarbon field, the SPM can be designated by the oil and gas safety authority (DGSUNMIG), chosen among universities or public research centres with proved skills. The SPM will act as an independent technical body supervising the monitoring projects; collecting, processing, interpreting data; and reporting to the ministerial authority, the local administrative authority, and to the industrial operator. Moreover, the SPM will contribute to the definition of specific boundaries of the survey volumes, reference thresholds and parameter values that should be adopted in specific decisional models. With this set-up, the ILG guidelines thus provide a guarantee for the impartiality and independence of the technical-scientific analysis, carried out by a neutral, unbiased, SPM, with respect to the owner of the production licence.

In case of reinjection of incompressible fluids (e.g. waste water; the ILG do not include gas storage in this case), the ILG prescribe a strict four-stage TLS, tied to fixed thresholds, and actions directly following exceedance of limits. Focussing on the Inner Domain, the ILG recommend to:

1. Proceed with ordinary activities and regularly report all events with magnitude less than the 'green' magnitude threshold $\mathrm{M}_{\text {GREEN }}$ (or corresponding PGV and PGA)

2. Re-analyse earthquake parameters (and all other data) after an event with magnitude exceeding $\mathrm{M}_{\text {GREEN }}$ (or corresponding PGV and PGA)

3. Reduce production after an event with magnitude between $\mathrm{M}_{\text {YELLOW }}$ and $\mathrm{M}_{\text {ORANGE }}$ (or corresponding PGV and PGA)

4. Immediately halt industrial operations in case of events with magnitude exceeding the orange level $\mathrm{M}_{\text {ORANGE }}$ (or corresponding PGV and PGA)

The ILG suggest indicative threshold values $\left(\mathrm{M}_{\text {GREEN }}=1.5, \mathrm{M}_{\text {YELLOW }}=2.2\right.$, and $\mathrm{M}_{\text {ORANGE }}=3.0$;

Table 1 Traffic Light System thresholds defined in the ILG

\begin{tabular}{llccc}
\hline Alert level & Traffic light & $\mathrm{M}_{\max }$ & $\begin{array}{l}\text { PGA } \\
{[\% \mathrm{~g}]}\end{array}$ & $\begin{array}{c}\text { PGV } \\
{[\mathrm{cm} / \mathrm{s}]}\end{array}$ \\
\hline 1 Ordinary & Green & $\leq 1.5$ & - & - \\
2 Attention & Yellow & $\leq 2.2$ & 0.5 & 0.4 \\
3 Reduction of activity & Orange & $\leq 3.0$ & 2.4 & 1.9 \\
4 Stop of activity & Red & $>3.0$ & 6.7 & 5.8 \\
\hline
\end{tabular}

see Table 1) and recommend that actual values be explicitly estimated at each individual site in consideration of the specific site characteristics, including the tectonic environment. Preliminary monitoring of background seismicity for at least 1 year before the new activity is started and a period of calibration of the monitoring procedures are also recommended. Observations are supposed to start 1 year before the new industrial activity to allow definition of a blank-level baseline. They must then continue for the entire duration, and last for at least 1 year after the end of industrial operations. The task of the monitoring system is to control seismic parameters, pore pressure, and ground deformation as well as those derived from them by further analyses, as e.g., PGA, PGV, number and/or frequency of seismic events, magnitude, or time-space evolution.

\subsection{Experimental application of the ILG}

According to the ISPRA (2014), human activities that can potentially induce earthquakes in Italy are mining, reservoir impoundment, geothermal energy production, gas storage, and hydrocarbon exploitation (extraction of oil and gas and re-injection of wastewater). Hydraulic fracturing is not practiced in Italy, because the suitable shale gas formations are lacking.

Figure 1 shows cases, either postulated or documented, of induced or triggered seismicity compiled by ISPRA (2014). Note, however, that according to Caciagli et al. (2015), the Caviaga earthquakes of 1951 can hardly be considered as due to the underground activities today (Caciagli et al., 2015). The white symbols represent additional sites of gas storage (squares) and low enthalpy geothermal energy production (triangle) from where so far; no seismicity has been reported (Braun et al. 2018b). In a three-year experimental phase, the ILG are planned to be tested in at least four different pilot areas (Fig. 1):

(i) Casaglia (Emilia Romagna, northern Italy) for lowenthalpy geothermal energy production

(ii) Minerbio (Emilia Romagna, northern Italy) for gas storage

(iii) Cavone (Emilia Romagna, northern Italy) for hydrocarbon extraction/waste water re-injection

(iv) Val d'Agri (Basilicata, southern Italy) for hydrocarbon extraction/waste water reinjection 
While the three cases of Casaglia, Minerbio, and Cavone directly reflect the interest of the ICHESE Commission about specific areas in Emilia-Romagna, implementation of an independent monitoring system for Val d'Agri is regulated by a specific agreement signed by MISE, INGV, and Regione Basilicata with the acceptance of the industrial operator.

For the abovementioned areas (ii.) - (iv.), DGSUNMIG nominated INGV as the agency, responsible for applying the ILG (Struttura Preposta al Monitoraggio, SPM). First experiences made during the recently concluded test-phase of the Minerbio concession are described by Carannante et al. (2019, this volume), who emphasize the improvement in earthquake detection capability due to the upgrade of the seismographic network of the plant operator linked to the requirements posed by ILG, and to the integration of available stations of the INGV national network. Other relevant cases in Italy, where geophysical monitoring has been extensively running for several years under systematic protocols, include the gas storage at Collalto (Priolo et al. 2015; Moratto et al. 2019; Romano et al. 2019) and the planned geothermal site of Torre Alfina (Braun et al. 2018a).

\section{Discussion on the application of the ILG}

Experimental application of the ILG is still ongoing, and results are not yet final (information is available on a specific site, maintained by the Italian Oil \& Gas Safety Authority - DGS - UNMIG, MISE: https://unmig.mise. gov.it/index.php/it/sicurezza/geomonitoraggi; last accessed: August 20, 2019).

In the following, we would like to point out some possibly critical issues in the application of the ILG that require special care in the implementation, concerning (i) adequacy of magnitude thresholds of TLS, and their relevance to Italian cases, (ii) interference between multiple anthropic activities in the same area, (iii) interactions between neighbouring exploitation licences, and (iv) significance of one-year period of pre-production background monitoring.

\subsection{Earthquake magnitudes in a traffic light system}

In the traffic light system, alert levels are defined on the basis of exceedance of threshold values for a few seismic parameters (magnitude, PGV, PGA; Dialuce et al.
2014). The ILG provide no constraint on the specific magnitude scale to use, so the local magnitude $\left(\mathrm{M}_{\mathrm{L}}\right)$ may seem the most appropriate and practical choice. In fact, to estimate the size of a seismic event, the INGV national scale monitoring system for tectonic earthquakes uses the local magnitude $\mathrm{M}_{\mathrm{L}}$, following the classical definition given by Hutton and Boore (1987). On the other hand, $\mathrm{M}_{\mathrm{W}}$ may seem an alternate, more significant estimator of source size. Malagnini and Munafò (2018) show that for the Italian Apennines, $\mathrm{M}_{\mathrm{W}}=2 / 3 \quad \mathrm{M}_{\mathrm{L}}+1.14-$ meaning that if the proposed ILG threshold values (1.5/2.2/3.0) are understood as relating to $\mathrm{M}_{\mathrm{L}}$, they may translate into $\mathrm{M}_{\mathrm{W}}=2.1 / 2.6$ / 3.1. Moment magnitude $\mathrm{M}_{\mathrm{W}}$ is only provided a few hours after the event, as additional information, when the seismic moment tensor is available for events of particular interest, but not for smaller events (the size of weak seismic events in Italian volcanic areas is sometimes quantified using yet another magnitude scale based on duration, $\mathrm{M}_{\mathrm{D}}$ ). In a rather promising alternate approach, Atkinson et al. (2014) proposed the computation of $\mathrm{M}_{\mathrm{w}}$ for weak local events based on the use of response spectra; a formulation that has later been applied to the weak seismicity of North-East Italy by Moratto et al. (2017). All these magnitude types (i.e. $\mathrm{M}_{\mathrm{L}}, \mathrm{M}_{\mathrm{D}}$ and $\mathrm{M}_{\mathrm{W}}$ ) are fundamentally different among them, and obviously not interchangeable. It should be noted that such thresholds, given in the ILG, are meant to be indicative and have to be fixed in all specific cases by the competent actors (monitoring agency, licence operator, ministry, local regional government) with a technical operational document (Documento di Gestione Operativa del Monitoraggio, DGOM) considering the seismotectonic setting of the area. However, the risk of potential ambiguities in magnitude, or subjective choices not supported by a standard regulatory protocol, could be source of contrasting judgements at time of possible alert step-up, and should be carefully addressed. As noted above, INGV uses the Hutton and Boore (1987) relation for $M_{L}$ at the national scale. However, this distance-dependent attenuation correction - although carrying the advantage of being a longstanding, reliable, reference - is not very well suited for the whole Italian region (Di Bona 2016). In particular, seismographic stations closer to the epicentre $(\sim$ tens of $\mathrm{km}$ ) systematically provide larger-magnitude values than farther stations. On one side, then, more reliable specific attenuation terms - particularly calibrated on the short distances that are relevant for the very local 
scale of oil/ gas reservoirs - should be devised for the sites object of monitoring. On the other side, it may not be desirable to publish different magnitudes, depending on the seismographic network used for analysis, for some critical earthquake, which may involve stopping industrial operations. As an example, we may mention recent experiences made in the geothermal area of Torre Alfina, where seismicity recorded by a local seismic network produced $\mathrm{M}_{\mathrm{L}}$ estimates that differ significantly from magnitudes determined by the National Seismic Network (Braun et al. 2018a). Depending on the geometrical distribution of the monitoring seismic network the application of accurate attenuation laws and correction factors strongly affects the estimation of $\mathrm{M}_{\mathrm{L}}$. This adds to uncertainty inherent in every magnitude estimate that may pose issues when using a fixed-threshold activation system as TLS.

The very significance of a TLS, based on magnitude or peak ground motion (PGV, PGA) thresholds, is mainly connected to hydraulic fracturing, or fluid extraction causing differential sediment compaction (e.g., Bommer et al. 2006; De Waal et al. 2015; Baisch et al. 2019). In fact, the principle of a TLS assumes gradual increase in magnitude of earthquakes with the duration of anthropic activities (i.e. volume of fluid transferred), so that major earthquakes (that may cause damages or concern, because of the ground shaking they produce) are preceded by weaker precursors, and hence, precautionary operational measures may mitigate the seismic hazard. It has been shown that the actual mechanism may be more complex even in hydraulic stimulations (Baisch et al. 2019), and application of such a TLS to cases of possibly triggered events - a major source of concern in tectonically-active Italian territory - is not proven conceptually (Bommer et al. 2015). A triggered event is such that stress build up is due to steady, longterm, ungovernable tectonic loading, while human endeavours may only provide a (possibly minute) contribution with an activation stress, triggering slip on a fault. Here, a threshold system on a sequence of earthquakes provides no forecast model. More sophisticated TLS systems, based on statistical forecast models, have also been proposed (Adaptive TLS, e.g. Mignan et al. 2017), but they require an event population numerous enough to allow statistical analyses, only available in hydraulic fracturing cases, where microearthquakes are often plentiful. When triggered events are a concern (quite common in Italy), perhaps a physics-based fluid-geo-mechanic reservoir model, updated with time and coupled with an active fault model, would represent a necessary requirement (although modelling of earthquake triggering is complex and highly dependent on, largely unknown, local geology and stress state).

\subsection{Multiple anthropic activity}

Different anthropic activities may insist on the same territory, in close geographical locations. Such an example is the Val d'Agri region (Basilicata, Southern Italy), one of the largest European onshore oil reservoirs, with reinjection of production water, where the local Basin Authority manages the artificial Pertusillo Lake reservoir, with seasonal water level variations of $\pm 40 \mathrm{~m}$ (Valoroso et al. 2009; Stabile et al. 2014b).

The Pertusillo impoundment (PI in Fig. 2) generates seismicity at the border between Inner and Extended domains of the Val d'Agri licence, with maximum recorded magnitude $\mathrm{M}_{\mathrm{L}}=3.3$ in the period from 2001 to 2017 - compared to maximum magnitude $\mathrm{M}_{\mathrm{L}}=1.8$ recorded in association to waste water injection at the Costa Molina 2 well (CM2 in Fig. 2; Stabile et al. 2014a; Improta et al. 2015). The event with maximum magnitude (red star, northeast of PI in Fig. 2) has likely not been generated by the activities of the hydrocarbon production, but is rather attributable to reservoirinduced seismicity, and failure to discriminate between the two sources in application of a TLS - and possible resulting limitations to operational industrial activities may have expensive consequences on the oil and gas production. On the other hand, the ILG have no regulatory power on water reservoirs. Concerning the seismicity observed in the NW part of the monitoring domains, Valoroso et al. (2009) report seismotectonic origins, indicating prevalent normal faults with antiApenninic strike.

\subsection{Neighbouring exploitation licences}

Identification of the process responsible for generating a seismic event becomes of particular interest in the case of adjacent production areas, operated by different companies. This is, e.g., the case in region Basilicata (southern Italy), where hydrocarbon reservoirs in Val d'Agri and Gorgoglione licences are exploited by different companies (Fig. 3).

While oil and gas extraction in the Val d'Agri licence is ongoing since 1993 (https://unmig.mise.gov.it/), 


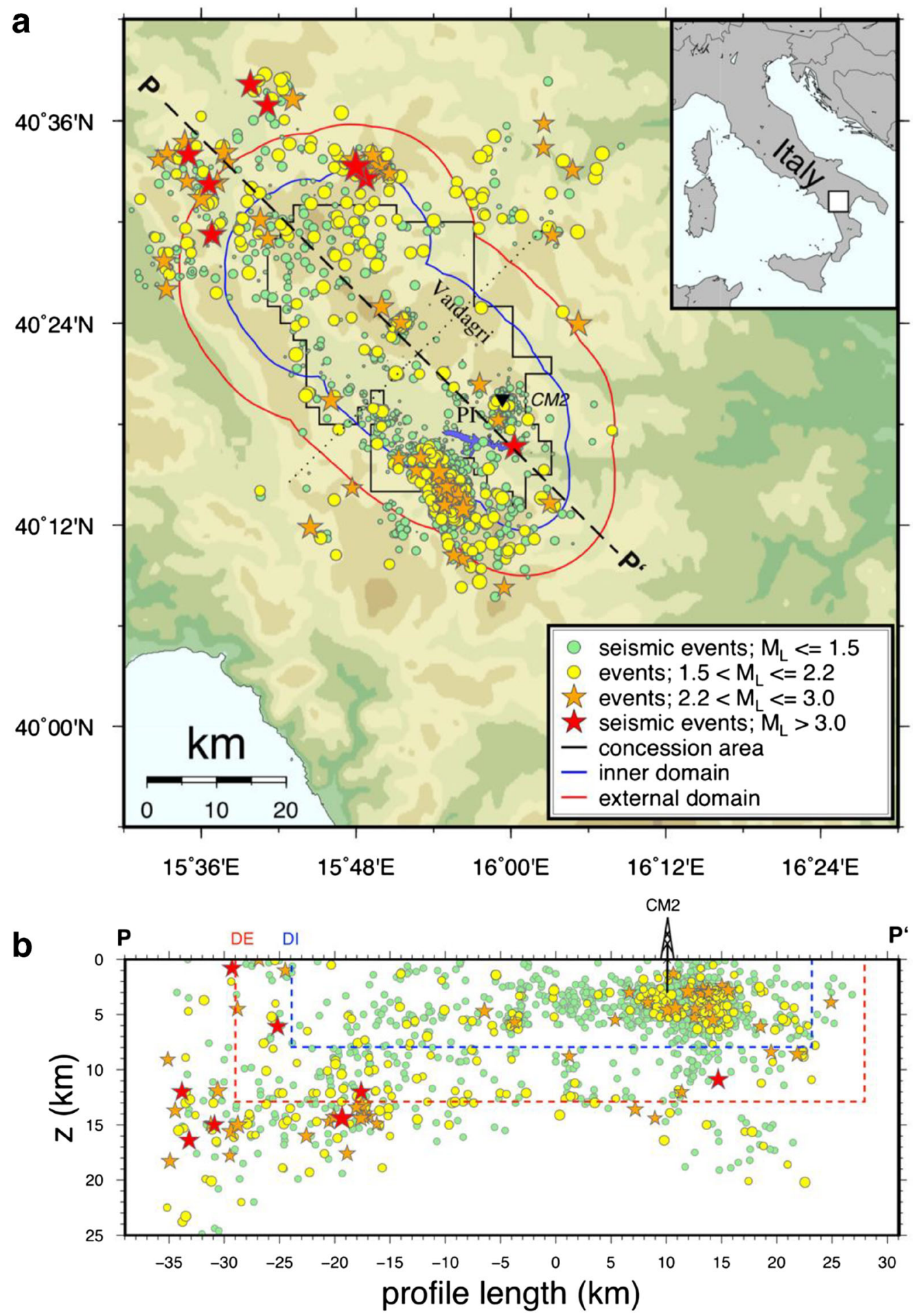

Fig. 2 (a) Epicentres (01/2001-09/2019) in the area of the hydrocarbon exploitation concession (black line) in Val d'Agri (data courtesy of ENI). Coloured lines represent the Inner Domain (oilwater contact, $\mathrm{OWC}+5 \mathrm{~km}$, blue) and the Extended Domain $(\mathrm{OWC}+10 \mathrm{~km}$, red), according to the ILG. Seismic events are represented by coloured magnitude-sized circles and stars according to the Table 1. PI=Pertusillo Impoundment; CM2 = reinjection well CM2. (b) Vertical profile showing the seismicity projected on the line PP' (projection width $\pm 20 \mathrm{~km}$, dotted line). Note that most of the seismicity reported below CM2 belongs to the projection of the seismic cluster located SW off PI 
Fig. 3 The concessions of Val d'Agri and Gorgoglione and their corresponding monitoring domains DI(red)/DE(blue); preliminary domain borders are represented by dashed lines (see text)

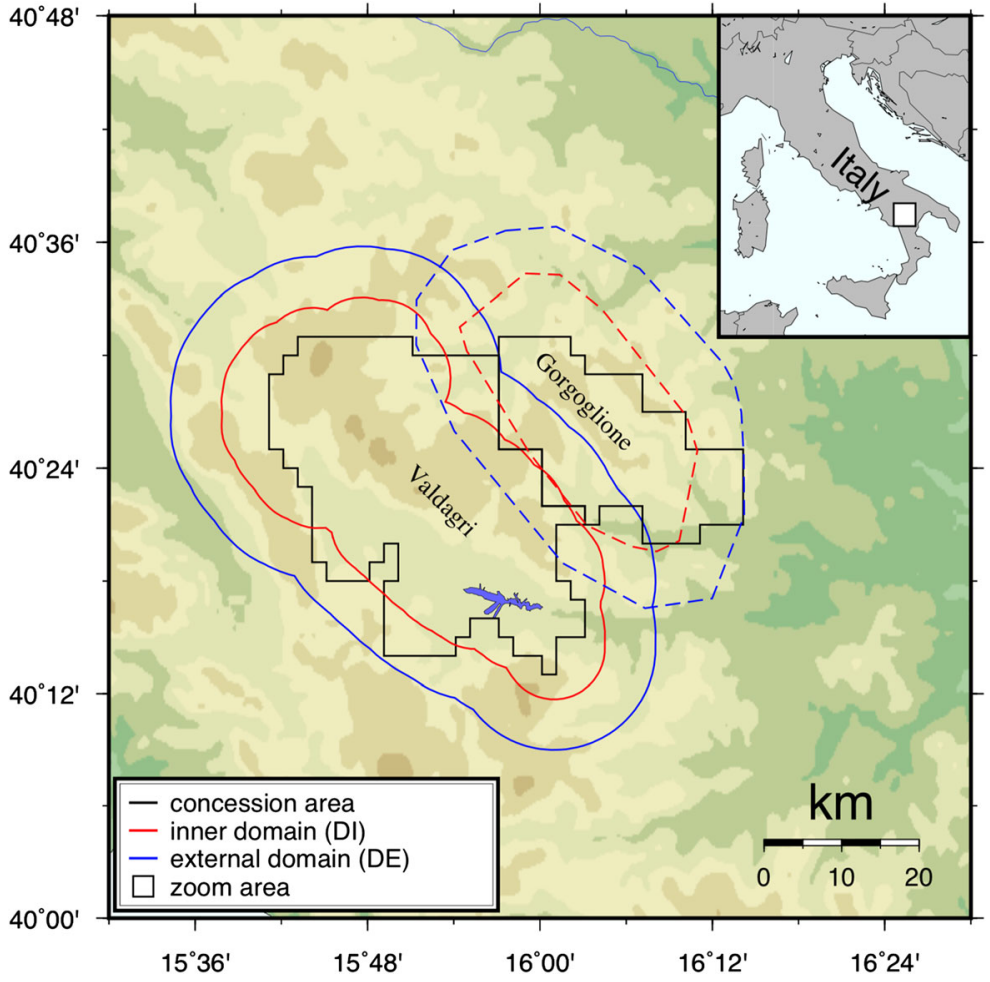

hydrocarbon production at Gorgoglione is scheduled to start imminently. For new licences, the ILG prescribe determination of the blank-level baseline of natural seismicity and ground deformation for at least 1 year prior to the start of the production. However, it cannot be excluded that the existing productive activity in Val d'Agri may induce stress variations into adjacent areas, perhaps on the site of the Gorgoglione licence, leading to a biased blank-level baseline. Besides, once the hydrocarbon production at Gorgoglione has started, it might become difficult to discriminate, whether seismic events or ground deformation are induced by one, or the other company, especially for phenomena occurring near the border of the adjacent permits. Although the two reservoirs are geologically independent, identification of possible responsibilities will be a big challenge. Should inner or external domains of neighbouring concessions overlap, any observed anomaly exceeding the TLS-threshold inside the monitoring domains leads to the prescribed consequences of all involved permits, according to the ILG. It may hence be advisable that neighbouring licences would be dealt with jointly, by the same monitoring agency. Besides, physics-based modelling might become necessary to discriminate between the two reservoirs, and to take appropriate decisions.
A similar situation exists in Central Italy (Tuscany, Umbria and Latium) for geothermal energy production licences, whose regulatory authorities are generally the regional governments. After publication of the ILG in 2014, new research permits have been issued, some of which designated "pilot concessions", and held by MISE under national supervision. The new permits are inside and around presently productive permits (orange and violet areas in Fig. 4), operated by one single company, in the areas of (1) Larderello-Travale, (2) Mount Amiata, (3) Latera (red areas in Fig. 4). The ILG (Terlizzese 2016) suggest to determine the blanklevel baseline for seismicity and ground deformation, even for small-footprint permits inside or adjacent to geothermal reservoirs that have been productive since decades.

In the case of a $\mathrm{M}_{\mathrm{W}}=3.7$ seismic event that occurred at Castelnuovo Val di Cecina on May 01, 2018 (yellow star 1 in Fig. 4), the epicentre is located inside the DI of the violet as well as the red permits (red area in Fig. 4, http:/terremoti.ingv.it/event/1910349). The question whether the event is part of the natural seismicity related to the seismotectonic activity of the area or may be connected to the geothermal exploitation of adjacent permits cannot be answered clearly, because 


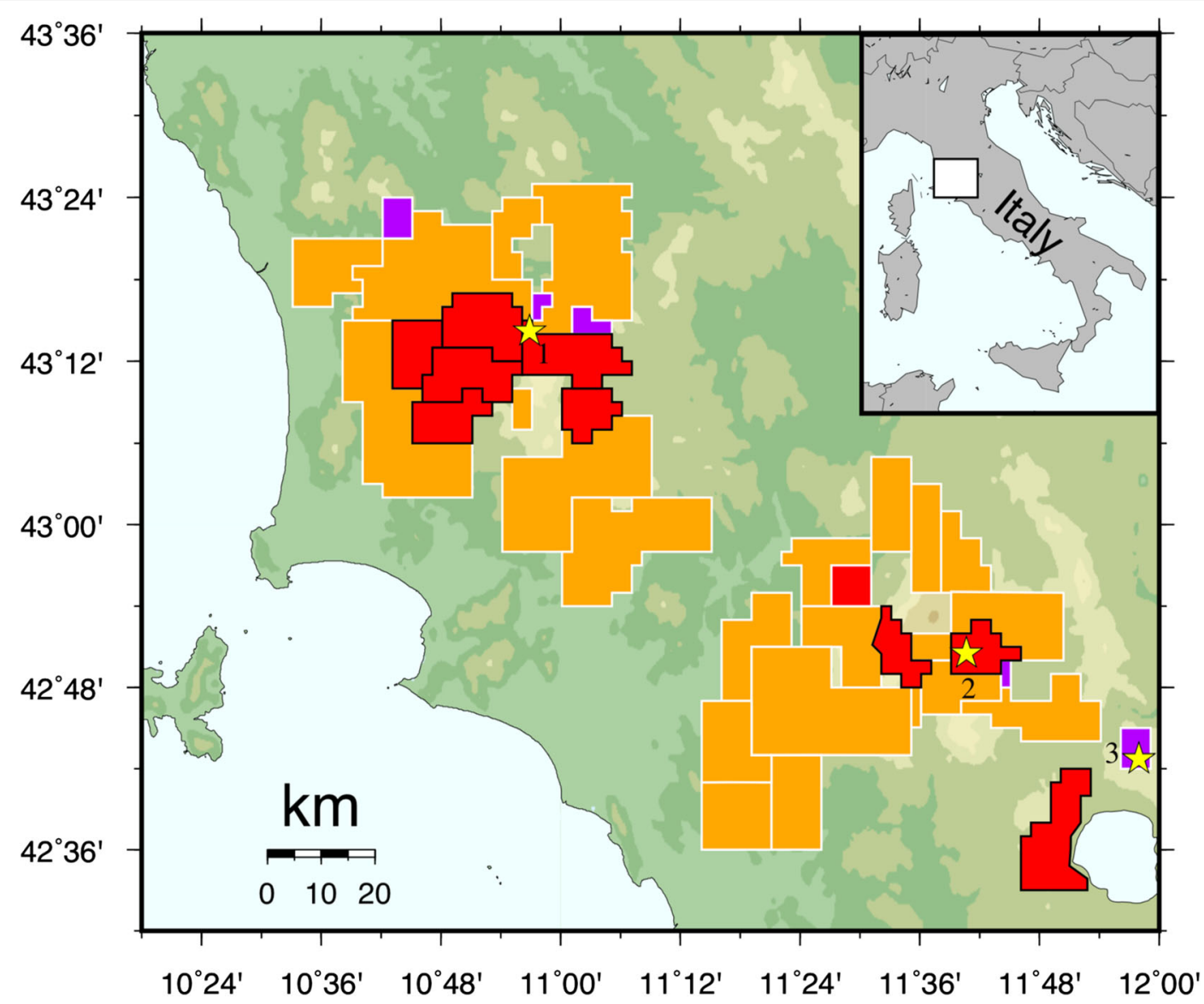

Fig. 4 Concessions of geothermal energy production around (1) Larderello - Travale, (2) Mt. Amiata, (3) Latera: red - production, orange - research permits, violet - pilot concessions. Yellow stars

both permits exploit the same geothermal reservoir. Seismicity in the area had already been observed long before the geothermal production started, reaching maximum magnitude $\mathrm{M}_{\mathrm{W}}=4.3$ on March, 21, 1925, as well as the $\mathrm{M}_{\mathrm{W}}=3.6$ event of June 24, 1990 (both, Rovida et al. 2016), occurred during production, had similar magnitude and location as the 2018 event, but gave no reason to stop operations (as in 2018 the ILG were not mandatory for the geothermal operator).

In case of adjacent production permits some critical questions may arise, such as:

- How to regulate the joint use of data owned by different companies?

- How to assess the possible interference between such activities?

- How to make transparent/public both data streams and information? indicate the respective largest seismic events ever recorded at (1) $\mathrm{M}_{\mathrm{w}}=3.7$, Larderello in 2018, (2) $\mathrm{M}_{\mathrm{w}}=4.5$, Mt. Amiata in 2000, (3) $\mathrm{M}_{\mathrm{w}}=4.1$, Torre Alfina in 2016

Hence, it might be advantageous if a single monitoring agency (SPM) is nominated for neighbouring permits, such that one single integrated monitoring system may manage nearby sites, even when exploited by different companies.

\subsection{One-year pre-production monitoring}

The ILG prescribe that preliminary seismic monitoring has to be carried out at least 1 year before extraction or underground storage of fluids, as a measure to evaluate natural background seismicity in unperturbed conditions. Then, only exploitation licences that have recently been granted would be subject to this prescription, while all running production that started before implementation of the ILG guidelines would obviously be exempt. This may be a critical point in the case where new operations are planned in the vicinity of productive areas, and preliminary seismic monitoring may be 
biased by nearby ongoing anthropic activities. In particular, licences for geothermal energy production often have a small geographical footprint in Tuscany, where the liberalization of the geothermal energy market opened the field to smaller private subjects. Figure 4 shows the orange and violet areas of new concessions located inside or adjacent to geothermal production areas that have been operated since decades. In this case, a truly unbiased preliminary assessment of background seismicity seems impossible. On the other hand, it is important to establish whether new activities generate a significant variation in the (background) seismicity. Given the general seismic hazard of most of the Italian territory, notable tectonic earthquakes may occasionally occur during the one-year pre-productive monitoring period, as in the case of the May 30, 2016, $\mathrm{M}_{\mathrm{L}}=4.1$ event at the proposed Torre Alfina geothermal area (area 3 in Fig. 4; Braun et al. 2018a), where production has never started. Given that any effort for better understanding the underlying seismotectonics of a region, where significant stress perturbation may result from planned or ongoing anthropic activities, is important and should be pursued as much as possible, we question the possible regulatory significance of a pre-production seismic survey of just one-year duration. On one side, 1 year is not enough to fully characterize background seismicity; on the other side, such a survey may be biased by nearby anthropic activities, or by an occasional occurrence of an earthquake that may hinder future activities. Application of ILG guidelines should explicitly worry about the consequences of the pre-production survey for the future exploitation, especially in case that significant seismic events occurred (e.g. $\mathrm{M}_{\mathrm{L}}=4.1$ at Torre Alfina).

However, the 1-year recommendation for the preactivity acquisition represents a compromise between the goal of achieving a fair picture of background seismicity, recorded by the local monitoring network, and the need to avoid a too long and demanding requirement in addition to many other technical and administrative duties.

\section{Conclusions}

Globally, induced seismicity is receiving increased interest, both by the scientific community and the general public, more and more concerned about the impact of natural and industrial risks in modern society. A thorough and continued examination of what the "best monitoring practices" could be is therefore timely and important. The ILG represents the first, very significant, attempt in Italy to regulate the monitoring of human activities in the subsoil. The test implementation phase at the pilot sites is therefore an important step that may help improve the protocol, point out critical questions, and clarify many potential site-specific issues.

In Italy extraction of oil and gas, as well as the production of geothermal energy, often implies that different operators exploit the same reservoirs, or adjacent ones. However, each single industrial company has to fulfil the prescriptions defined by the ILG, to set up an autonomous monitoring system for continuous monitoring of seismicity, ground deformation, and pore pressure, each to be controlled by an independent monitoring agency (SPM). We point out that it could be advantageous to manage geographically adjacent sites in a single monitoring system, to enable a better global view and avoid artificial hard borders between processes. In case of contiguous productive areas (Fig. 4), the ILG's obligation for new exploitation licences to determine the blank-level baseline 1 year before starting the production may not be exhaustive. For companies with upcoming exploitation licences, it is impossible to determine the natural background seismicity or the ground deformation, excluding any possible bias by ongoing productive activities in neighbouring concessions. Data sharing among operators of contiguous productive concessions is a need for a significant assessment.

The definition of the domains and the level transition in the reaction scheme represent key-points for the interpretation of possible phenomena recognized by the monitoring, As a first approximation, such volumes are purely defined in geometrical terms. The complexity of the geophysical context of natural and induced effects would require that the domain volumes are defined individually on the basis of the analysis of long-term seismicity time series and geo-mechanical characteristics of the reservoir.

Noticeably, the ILG define a formal framework for drawing and implementing efficient monitoring schemes at a very general level providing large autonomies (and related responsibilities) to the concerned institution. In particular and special cases, such as the existence of adjacent permits that insist on neighbouring domains, it may be advisable to promote a cooperative, supervising, and coherent planning of activities. In particular, concerning adjacent industrial activities and potential 
mutual interference on background seismicity, as the guidelines require one-year long preliminary seismic observations as a measure for the evaluation of background seismicity in unperturbed conditions, it would be probably appropriate to widen the meaning of the term "unperturbed" to "natural or already perturbed" seismicity.

Should domains of neighbouring concessions overlap, it is our opinion that the automatic activation of alert level for both the involved industrial subjects should be given great care. It would be desirable that all imaginable efforts are made to carefully evaluate how to ascribe possible observable variations to one or another industrial subject, especially in case of exploitation of independent reservoirs.

The recommendation to determine the blank level baseline of natural background seismicity and ground deformation during a one-year lasting period prior to exploitation may not be sufficiently long. The possible absence of any seismicity during this period is not significant; therefore an evaluation of the previous instrumental, and even historical, seismicity should be possibly included. On the other hand, in case that during the pre-production phase seismicity or ground deformation show significant variations, as, e.g., in May 2016 at Torre Alfina, the ILG do not describe any consequences or constraints concerning the future exploitation.

Further critical points on implementation of ILG concern the use of magnitude thresholds for a TLS. Different formulas can be used for the calculation of the magnitude, with no obvious best choice, and uncertainty is inherent in any estimate. For the case of local magnitude, $\mathrm{M}_{\mathrm{L}}$, it strongly depends on local attenuation and network configuration (Di Bona 2016; Braun et al. 2018b). Best- practice guidelines are hence challenged to be actionable and precise, but at the same time, they should not assign disproportionate meaning and consequence to, say, the decimal digit of a numerical value. For this and the other issues, possible suggestions for improvement may stem from a discussion among all the actors involved in the system.

We may also question the meaning of a traffic light system, with thresholds set on magnitude or ground motion parameters (PGV, PGA), for triggered seismicity - a common concern in tectonically active Italy - as it is based on a forecast model that primarily applies to earthquakes induced by hydraulic fracturing (e.g. Baisch et al. 2019).

We conclude with a final comment on the merits of the ILG. As already pointed out, they represent an excellent framework for coherent monitoring of hydrocarbon and geothermal sites at a national scale, and started a wide-scale, authoritative, and cogent debate on the possible impacts of underground energy technologies in Italy. A planned new version of ILG guidelines, revised after the test implementation, will overcome issues and questions that may have risen during the test implementation period. As a long-term goal, on the basis of the recorded data (seismic, ground deformation, pore pressure), the refined geological and fluid-geomechanical models of the reservoir, combined with ground motion prediction equations, the analysis and evaluation of hazard may be updated in quasi-real-time enabling to pass finally from a static to a dynamic risk treatment.

Acknowledgements We are grateful to C. Doglioni for comments and suggestions, and we would like to thank F. Terlizzese, the former General Director of the "Directorate-General for Safety of Mining and Energy Activities" of the Italian Ministry of Economic Development (MISE/DGS-UNMIG), for the fruitful collaboration. We appreciate important suggestions by M. Picozzi and an anonymous reviewer, which significantly improved the manuscript. We are further grateful to I. Antoncecchi, S. Grandi and M. Mileti for discussions. This research was financed by the "Accordo Operativo 2018-19 INGV MISE/DGS/UNMIG" e "Protocollo d'Intesa tra la Regione Basilicata e INGV” (Rep. N 886, 08/11/2018).

Open Access This article is licensed under a Creative Commons Attribution 4.0 International License, which permits use, sharing, adaptation, distribution and reproduction in any medium or format, as long as you give appropriate credit to the original author(s) and the source, provide a link to the Creative Commons licence, and indicate if changes were made. The images or other third party material in this article are included in the article's Creative Commons licence, unless indicated otherwise in a credit line to the material. If material is not included in the article's Creative Commons licence and your intended use is not permitted by statutory regulation or exceeds the permitted use, you will need to obtain permission directly from the copyright holder. To view a copy of this licence, visit http://creativecommons.org/licenses/by/4.0/.

\section{References}

Antoncecchi I, Cappelletti F, Chiarabba C, Doglioni C, Gasparini P, Lanari R, Priolo E, Zollo A, Di Bucci D, Terlizzese F, Dialuce G, Panei L (2017) Lessons learned after the 2012 Emilia earthquakes (Italy) in matter of Hydrocarbon E\&P and gas storage monitoring. In: 16th world conference on earthquake - 16WCEE 2017, Santiago (Chile), January 9-13, 2017; paper ID 4260

Astiz L, Dieterich J, Frohlich C, Hager B, Juanes R, Shaw J (2014) On the potential for induced seismicity at the Cavone oilfield: analysis of geological and geophysical data, and 
Geomechanical modeling. Technical Report. Report for the Laboratorio di Monitoraggio Cavone. http://labcavone. it/documenti/32/allegatrapporto-studiogiacimento.pdf (last accessed: August 19, 2019)

Atkinson G, Wesley Greig D, Yenier E (2014) Estimation of moment magnitude $(M)$ for small events $(M<4)$ on local networks. Seismol Res Lett 85:1116-1124

Baisch S, Koch C, Muntendam-Bos A (2019) Traffic light systems: to what extent can induced seismicity be controlled? Seismol Res Let 90(3):1145-1154. https://doi.org/10.1785 /0220180337

Bommer JJ, Oates S, Cepeda JM, Lindholm C, Bird J, Torres R, Marroquín G, Rivas J (2006) Control of hazard due to seismicity induced by a hot fractured rock geothermal project. Eng Geol 86:287-306

Bommer JJ, Crowley H, Pinho R (2015) A risk-mitigation approach to the management of induced seismicity. J Seismol 19:623-646. https://doi.org/10.1007/s10950-015-9478-z

Braun T, Caciagli M, Carapezza M, Famiani D, Gattuso A, Lisi A, Marchetti A, Mele G, Pagliuca NM, Ranaldi M, Sortino F, Tarchini L, Kriegerowski M, Cesca S (2018a) The seismic sequence of $30^{\text {th }}$ may - $9^{\text {th }}$ June 2016 in the geothermal site of Torre Alfina (Central Italy) and related variations in soil gas emissions. J Volcanol Geotherm Res 359:21-36. https://doi. org/10.1016/j.jvolgeores.2018.06.005

Braun T, Cesca S, Kühn D, Martirosian-Janssen A, Dahm T (2018b) Anthropogenic seismicity in Italy and its relation to tectonics: state of the art and perspectives. Anthropocene 21: 80-94. https://doi.org/10.1016/j.ancene.2018.02.001

Caciagli M, Camassi R, Danesi S, Pondrelli S, Salimbeni S (2015) Can we consider the 1951 Caviaga (northern Italy) earthquakes as non-induced events? Seismol Res Lett 86. https://doi.org/10.1785/022015000110pp

Carannante S, D'Alema E, Augliera P, Franceschina G (2019) Improvement of microseismic monitoring at the gas storage concession "Minerbio Stoccagio" (Bologna, northern Italy). J Seis This volume

Cartlidge, E. Human Activity May Have Triggered Fatal Italian Earthquakes, Panel Says. Science (80-). 344, 141-141 (2014).

Cesca S, Braun T, Maccaferri F, Passarelli L, Rivalta E, Dahm T (2013a) Source modelling of the M5-6 Emilia-Romagna, Italy, earthquakes (2012 may 20-29). Geophys J Int 193: 1658-1672. https://doi.org/10.1093/gji/ggt069

Cesca S, Rohr A, Dahm T (2013b) Discrimination of induced seismicity by full moment tensor inversion and decomposition. J Seismol 17(1):147-163. https://doi.org/10.1007 /s10950-012-9305-8

Ciccone F, Priolo E, Teofilo G, Antoncecchi I, Lanari R (2017) Seismic monitoring of underground activities for energy production: Survey of the existing facilities with reference to the Italian monitoring guidelines. Geoingegneria Ambientale e Mineraria 152(3):69-72 Society of Petroleum Engineers - SPE/IATMI Asia Pacific Oil and Gas Conference and Exhibition 2017

Dahm T, Becker D, Bischoff M, Cesca S, Dost B, Fritschen R, Hainzl S, Klose CD, Kühn D, Lasocki S, Meier T, Ohrnberger M, Rivalta E, Wegler U, Husen S (2013) Recommendation for the discrimination of human-related and natural seismicity. J Seismol 17(1):197-202

Dahm T, Cesca S, Hainzl S, Braun T, Krüger F (2015) Discrimination between induced, triggered and natural earthquakes close to hydrocarbon reservoirs: a probabilistic approach based on the modeling of depletion-induced stress changes and seismological source parameters. J Geophys Res B2 120:2491-2509. https://doi.org/10.1002/2014JB011778

Davis SD, Frohlich C (1993) Did (or will) fluid injection cause earthquakes? - criteria for a rational assessment. Seismol Res Lett 64(3-4):207-224

De Waal JA, Muntendam-Bos AG, Roest JPA (2015) Production induced subsidence and seismicity in the Groningen gas field - can it be managed? Proc. IAHS 372:129-139. https://doi. org/10.5194/piahs-372-129-2015

Di Bona M (2016) A local magnitude scale for crustal earthquakes in Italy. Bull Seismol Soc Am 106(1):242-258. https://doi. org/10.1785/0120150155

Dialuce G, Chiarabba C, Di Bucci D, Doglioni C, Gasparini P, Lanari R, Priolo E, Zollo A (2014) Indirizzi e linee guida per il monitoraggio della sismicità, delle deformazioni del suolo e delle pressioni di poro nell'ambito delle attività antropiche. GdL MISE, Roma. unmig.mise.gov.it/unmig/agenda/upload/85_238. pdf (English version at: https://unmig.mise.gov. it/images/docs/151_238.pdf; last accessed: August 20, 2019)

Doglioni C (2018) A classification of induced seismicity. Geosci Frontiers 9(6):1903-1909. https://doi.org/10.1016/j. gsf.2017.11.015

Ellsworth W (2013) Injection-induced earthquakes. Science:341. https://doi.org/10.1126/science.1225942

Foulger GR, Wilsona MP, Gluyasa JG, Juliana BR, Davies RJ (2017) Global review of human-induced earthquakes. Earth Sci Rev. https://doi.org/10.1016/j.earscirev.2017.07.008

Grigoli F, Cesca S, Priolo E, Rinaldi AP, Clinton JF, Stabile TA, Dost B, Fernandez MG, Wiemer S, Dahm T (2017) Current challenges in monitoring, discrimination, and management of induced seismicity related to underground industrial activities: a European perspective. Rev Geophys 55:310-340. https://doi.org/10.1002/2016RG000542

Hutton LK, Boore DM (1987) The $\mathrm{M}_{\mathrm{L}}$ scale in Southern California. Bull Seismol Soc Am 77:2074-2094

ICHESE (2014) International commission on hydrocarbon exploration and seismicity in the Emilia region: report on the hydrocarbon exploration and seismicity in Emilia region, February 2014, http://geo.regione.emilia-romagna. it/gstatico/documenti/ICHESE/ICHESE_Report.pdf (last accessed: August 19, 2019)

Improta L, Valoroso L, Piccinini D, Chiarabba C (2015) A detailed analysis of wastewater induced seismicity in the Val d'Agri oil field (Italy). Geophys Res Lett 42:2682-2690. https://doi. org/10.1002/2015GL063369

ISPRA (2014) Rapporto sullo Stato Delle Conoscenze Riguardo Alle Possibili Relazioni Tra Attività Antropiche e Sismicità Indotta/Innescata in Italia. Technical Report ISPRA, Roma, Italy, 71pp. http://www.isprambiente.gov.it/files/notizieispra/notizia-2014/rapporto-sismicita-indotta-innescata-initalia/Rapporto_sismicita_indotta_innescata_in_italia.pdf (last accessed: August 20, 2019 )

Juanes, R., Jha, B., Hager, B. H., Shaw, J.H. Plesch, A., Astiz, L., Dieterich, J. H., and Frohlich, C., 2016. Were the May 2012 Emilia-Romagna earthquakes induced? A coupled flowgeomechanics modeling assessment, Geophys. Res. Lett., 43, 6891-6897. https://doi.org/10.1002/2016GL069284

LabCavone (2019) http://labcavone.it . Accessed 20 August 2019 
Macini P, Mesini E, Panei L, Terlizzese F (2015) Land subsidence, seismicity and pore pressure monitoring: the new requirements for the future development of oil and gas fields in Italy, Proc. IAHS 372:533-538. https://doi.org/10.5194/piahs-372533-2015

Macini P, Mesini EN, Antoncecchi I, Terlizzese F (2017) Guidelines for the environmental monitoring of oil and gas industry in Italy: seismic, ground deformation and reservoir pressure measurements. SPE/IATMI Asia Pacific oil and gas conference and exhibition 2017, Jakarta (Indonesia), October 17-19, 2017, volume 2017. Document ID: SPE-186258-MS; https://doi.org/10.2118/186258-MS

Malagnini L, Munafò I (2018) On the relationship between $\mathrm{M}_{\mathrm{L}}$ and $\mathrm{M}_{\mathrm{W}}$ in a broad range: an example from the Apennines. Italy Bull Seismol Soc Am 108(2):1018-1024. https://doi. org/10.1785/0120170303

McGarr A, Simpson D, Seeber L (2002) Case histories of induced and triggered seismicity. In: International handbook of earthquake and engineering seismology, chap. 40. Academic Press, London, pp 647-664

Mignan A, Broccardo M, Wiemer S, Giardini D (2017) Induced seismicity closed-form traffic light system for actuarial decision-making during deep fluid injections'. Scientific Rep 7(1):13607. https://doi.org/10.1038/s41598-017-13585-9

Moratto L, Saraò A, Priolo E (2017) Moment magnitude (mw) estimation of weak seismicity in northeastern Italy. Seismol Res Lett 88:1455-1464

Moratto L, Romano MA, Laurenzano G, Colombelli S, Priolo E, Zollo A, Saraò A, Picozzi M (2019) Source parameter analysis of microearthquakes recorded around the underground gas storage in the Montello-Collalto area (southeastern Alps, Italy). Tectonophysics 762:159-168

Priolo E, Romanelli M, Plasencia Linares MP, Garbin M, Peruzza L, Romano MA, Marotta P, Bernardi P, Moratto L, Zuliani D, Fabris P (2015) Seismic monitoring of an underground natural gas storage facility: the Collalto seismic network. Seismol Res Lett 86(1):109-123 + esupp. https://doi. org/10.1785/0220140087

Romano MA, Peruzza L, Garbin M, Priolo E, Picotti V (2019) Microseismic portrait of the Montello thrust (southeastern
Alps, Italy) from a dense, high-quality seismic network. Seismol Res Let 90(4):1502-1517. https://doi.org/10.1785 /0220180387

Rovida A, Locati M, Camassi R, Lolli B, Gasperini P (2016) CPTI15, the 2015 version of the parametric catalogue of Italian earthquakes. Istituto Nazionale di Geofisica e Vulcanologia. https://doi.org/10.6092/INGV.IT-CPTI15

Scognamiglio L, Margheriti L, Mele FM, Tinti E, Bono A, De Gori P, Lauciani V, Lucente FP, Mandiello AG, Marcocci C, Mazza S, Pintore S, Quintiliani M (2012) The 2012 Pianura Padana Emiliana seismic sequence: locations, moment tensors and magnitudes. Ann Geophys 55(4):549-559. https://doi.org/10.4401/ag-6159

Stabile TA, Giocoli A, Perrone A, Piscitelli S, Lapenna V (2014a) Fluid injection induced seismicity reveals a NE dipping fault in the southeastern sector of the high Agri Valley (southern Italy). Geophys Res Lett 41. https://doi.org/10.1002/2014 GL060948

Stabile TA, Giocoli A, Lapenna V, Perrone A, Piscitelli S, Telesca L (2014b) Evidences of Low-Magnitude Continued Reservoir-Induced Seismicity Associated with the Pertusillo Artificial Lake (Southern Italy). Bull Seismol Soc Am 104(4):1820-1828., August 2014. https://doi.org/10.1785 $/ 0120130333$

Terlizzese F (2016) Ottobre. Linee guida per l'utilizzazione della risorsa geotermica a media e alta entalpia. GdL MISE, Roma. http://www.cngeologi.it/wp-content/uploads/2016/10/Linee guida_geotermia.pdf

Valoroso L, Improta L, Chiaraluce L, Di Stefano R, Ferranti L, Govoni A, Chiarabba C (2009) Active faults and induced seismicity in the Val d'Agri area (southern Apennines, Italy). Geophys J Int 178:488-502. https://doi.org/10.1111/j.1365246X.2009.04166.x

Publisher's note Springer Nature remains neutral with regard to jurisdictional claims in published maps and institutional affiliations. 